\title{
Trend and Growth of Capital Stock in Bihar During 1980-2017
}

\author{
Jitendra Kumar Sinha, ${ }^{1, *}$, Anurodh Kumar Sinha ${ }^{2}$ \\ ${ }^{1}$ Ex. Senior Joint Director \& Head, DES, Bihar, India. \\ ${ }^{2}$ MIS \& Documentation Officer, PHIA Foundation, Bihar, India.
}

How to cite this paper: Jitendra Kumar Sinha, Anurodh Kumar Sinha. (2020) Trend and Growth of Capital Stock in Bihar During 1980-2017. Journal of Humanities, Arts and Social Science, 4(1), 57-66.

DOI: $10.26855 /$ jhass.2020.01.008

Received: April 24, 2020

Accepted: May 26, 2020

Published: June 19, 2020

*Corresponding author: Jitendra Kumar Sinha, Ex. Senior Joint Director \& Head, DES, Bihar, India.

Email: jksinha2007@rediffmail.com

\begin{abstract}
This paper attempts to generate time series estimates of net fixed capital stock at disaggregate and aggregate level for Bihar for the period from 1980-81 to 2016-17 based on Kruger’s Approach (2003) to estimate initial capital stock and then the Perpetual Inventory Method (PIM) for subsequent years. The estimates measure the extent to which production activity increases wealth and creates the conditions needed to continue the production of goods and services in future. Bihar underwent a massive accelerated growth performance in generation of capital stock in Aggregate since occurrence of turning point in 2005-06. Growth of capital stock in Secondary Sector was lower than the overall economy but that in Tertiary Sector specially Transport; Storage \& Communication; Trade, Hotel \& Restaurant witnessed higher growth pattern since occurrence of turning point in 2005-06. Primary Sector, which has about one-fifth share in capital stock, showed decelerated growth performance since occurrence of turning point in 2000-01. Since capital stock is known to be the engine of growth, decelerated growth performance of primary sector (mainly agriculture in Bihar) and lower growth performance in secondary sector (manufacturing, electricity \& construction) is a matter of concern for policy makers in the light of need of strong agriculture sector for Food Security and industrial \& infrastructure development. Decelerated trend in capital stock during Twelfth Plan is also a matter of concern for developing economy of Bihar. There is dire need to focus on reorientation of investment planning and strategy.
\end{abstract}

\section{Keywords}

Net Fixed Capital Stock, Perpetual Inventory Method, Relative Growth Rate, Turning Points

\section{Introduction}

Capital is the basic input in production that provides a flow of services over several time periods, often lasting decades whose accumulation over time leads to capital stock. Fixed capital stocks is the most important indicator of the extent to which production activity increases wealth and creates the conditions needed to continue the production of goods and services in future. The quality and quantity of fixed capital influences not only the productivity of capital itself, but also that of labour and total output. It has two basic roles as measure of wealth and measure of contribution of capital to production.

Fixed capital stock comprises all durables, reproducible tangible fixed assets—such as residential and non-residential buildings, dams, irrigational \& flood control projects, other constructional works, transport 
equipments, machinery \& equipments, breeding stocks, draught animals, dairy cattle, capital expenditure on land improvement, plantation, orchard development, a forestation, etc., which are used in production of goods \& services. It also include uncompleted construction assets; inventories of goods producing industries, trade, other industries and government; finished and semi-finished goods and young livestock except breeding stocks, dairy cattle \& like-which form part of the fixed assets. However, the durable assets in the hands of households which are not used for further production of goods and services such as automobiles, refrigerators, washing machines, furniture, sewing machines, etc., as well as fixed assets mainly meant for defense purposes do not form part of the fixed capital stock as these are assumed to have been consumed as soon as they are purchased. However, the construction works undertaken by the households and capital expenditures on residential dwellings for defense personnel, border roads, ordnance factories etc., form part of the fixed capital stock. Thus, the capital stock is a broad measure of the existing physical capital in an economy and it should increase as it develop and grows richer. The change in the capital stock is one of the fundamental ingredients of economic growth. It tells us that economies build up their capital stock-and therefore their real GDP-by devoting enough output to new investment to both replace worn out capital and then add some more.

Official estimates of Net Capital Stock and Net Fixed Capital Stock are compiled by the Central Statistical Office, Government of India. Details of methodology and sources of data used in preparation of these estimates have been documented in the publication, "National Accounts Statistics: Sources \& Methods, 2012". However, estimates of capital stock are not available at the state level for most of the states in India. Of course, measuring the capital stock has proved difficult and has generated raging controversy within the Economists \& Statisticians. By and large, two methods are employed — an evaluation of stock of capital through direct surveys or the more indirect Perpetual Inventory Method (PIM). Dholakia $(1974,1977)$ conducted a detailed study on sources of growth for Indian Economy for which Capital Stock series was generated through PIM. Nehru \& Dhareshwar (1993) described the derivation of a new database of physical capital stock estimates for a selected group of 92 developing and industrial countries from 1960 to 1990. Modified Harberger's approach (1978) was considered as the most appropriate one-out of several alternative techniques evaluated for the estimation of an initial capital stock. Bosworth, Collins \& Chen (1995) decomposed the growth of output per worker into the contribution from accumulation of physical and human capital, and from increase in total factor productivity (TFP). Many studies [Cororation \& Caparas (1999); Pradhan \& Barik (1999); Singh(2001); Wu \& Xu (2002); Kruger (2003); Das (2004); Golder (2004); Liman\& Miller (2004); Mussa(2006) ; and Rajeshwari (2008)] have dealt the construction of estimates of capital stock in the context of Indian and other economies, confined at the national level only. However, Singh \& Kaur (2012) undertook the task of constructing time series estimates of capital stock for Punjab \& Haryana states. The present study was undertaken with the objective of updating and constructing time series estimates of capital stocks for Bihar estimated earlier by Sinha \& Verma (2015b) and examining long-term trend behavior therein.

\section{Data}

1. Time series data on aggregated/disaggregated Gross State Domestic Product (GSDP) and Net State Domestic Product (NSDP) for Bihar were collected from the DES, Bihar for 1980-81 to 2016-17 and adjusted at constant prices (2011-12).

2. The DES, Bihar does not compile comparable data on Gross Capital Formation. However, Sinha \& Verma (2015a) estimated Gross Fixed Capital Formation (GFCF) at constant prices (2004-05) for 2004-05 to 2011-12. Methodology used by Sinha \& Verma (2015b) were adopted to obtain comparable series from 1980-81 to 2016-17 at 2011-12 prices. Aggregation were made into major sectors:

Primary (P): Agriculture; Forestry \&Logging; Fishing.

Secondary (S): Manufacturing; Construction; Electricity, Gas, \& Water Supply.

Tertiary (T1): Transport, Storage \& Communication; Trade, Hotel \& Restaurant.

Tertiary (T2): Banking \& Insurance; Real Estate, Ownership of Dwelling \&Business.

Services; Public Administration.

Tertiary Aggregate (T): T1 + T2.

Aggregate Capital Formation: P + S + T.

\section{Methodology}




\subsection{Estimation of Capital Stock}

The Perpetual Inventory Method (PIM) has been used to estimate the value of physical capital stock of the overall economy of Bihar as well as of an individual sector. In practice, it involves in beginning with a benchmark stock value for capital held (at constant prices) to which year-by-year known additions to stock (i.e., capital formation at constant prices) as well as depreciations adjusted to constant prices are subtracted period-by-period. In this way, a series is obtained for the capital stock in a given sector/overall economy.

Initial capital stock (K0) was worked out for the year 1980, through the Kruger Approach (2003):

$$
\mathrm{K} 0=[\operatorname{Io}(1+\mathrm{g}) /(\mathrm{g}+\mathrm{d})]
$$

Where, Io: Amount of Investment in the initial period.

g: Average annual compound rate of growth in Investment over the subsequent five years.

d: Depreciation rate.

Depreciation rate was estimated following Nehru \& Dhareshwar (1993) Approach as:

$$
\mathrm{d}=\frac{(\mathrm{D} / \mathrm{Y}) \cdot \mathrm{r}}{(\mathrm{I} / \mathrm{Y})-(\mathrm{D} / \mathrm{Y})}
$$

Where D: GSDP-NSDP

Y: GSDP; I: GFCF

r: rate of growth of GSDP.

Net fixed capital stock (NFCS) of the subsequent years was obtained as:

$$
\mathrm{K}_{\mathrm{t}}=(1-\mathrm{d}) . \mathrm{K}_{\mathrm{t}-1}+\mathrm{I}_{\mathrm{t}}
$$

Where $\mathrm{K}_{\mathrm{t}}$ : Capital Stock at time $\mathrm{t}$, and $\mathrm{I}_{\mathrm{t}}$ for investment at time period $\mathrm{t}$.

\subsection{Trend Analysis}

An in depth treatment of the pace and pattern of growth in capital stock in Bihar were traced through curves of the best-fit chosen from amongst the following seven functional forms in each of the components of NFCS :

$$
\begin{aligned}
& \text { Simple linear (SLR):Parabolic (PRB ) } \\
& \text { Cubic(CUB): Exponential (EXP) } \\
& \text { Log-Linear (LLR ): Log-Cubic (LCB ) } \\
& \text { Modified Exponential (MEX). }
\end{aligned}
$$

Curves of the best-fit were identified by the highest value of the indicator I [Sethi (2008); Ware \& Moon (1982)] given as:

$$
\mathrm{I}=1.2 \varnothing-0.2[\text { [ DW- } 2\}] \text {. }
$$

Where DW stands for Durbin-Watson's statistic; and $\varnothing=1-$ (Residual SS/Total CorrectedSS). I is the co-efficient of predictability.

\subsection{Relative Growth Rate}

Relative growth rates for the components of NFCS were computed at different points of time so as to examine various alternative hypotheses regarding behavioral growth path traced by the component. In the so identified growth paths of the best- fit followed by different components of NFCS, turning points, if any, were detected by following the methodology as outlined by Sethi (2010).

\subsection{Turning Points}

The pattern and nature of relative growth rates as reflected in the previous section in respect of various component of net fixed capital stock indicate to identify (if any) turning points, and kinked growth rates at the points as well as pooled growth rates over the study span following, Boyce (1986) and Sethi (2010) approach. With one kink, growth rates in two segments of time series $\{\mathrm{Yt}\}$ on a given component of net fixed capital stock were worked out through the following equation:

$$
\text { In } Y t=\beta o+\beta_{1}\left(D_{1} t+D_{2} k\right)+\beta_{2}\left(D_{2} t-D_{2} k\right)+u t
$$


Where $\mathrm{k}$ is the point in time at which turning point occurred. $\mathrm{D}_{1}$ and $\mathrm{D}_{2}$ are dummies that assume the value 0 and 1 alternatively in first part and second part of the two segments. The OLS estimatorsof $\beta_{1} \& \beta_{2}$ in equation (5) could generate the kinked growth rates, while the pooled growth rate is generated by the OLS estimator $\beta$ in the equation:

$$
\text { In } \mathrm{Yt}=\beta \mathrm{o}+\beta_{1} \mathrm{t}+\mathrm{ut} \text {. }
$$

Statistical significance of the growth rate was tested following Sethi (2008). Analysis was carried out through relevant computer programming.

\section{Estimates of NFCS}

Estimates of NFCS based on the methodology discussed in the previous section were generated for each of the components, viz., Primary, Secondary, Tertiary I, Tertiary II, Tertiary (Aggregate), \& Aggregate have been presented in Appendix and sectorial graphical positions are depicted in Figure 1(a-f):

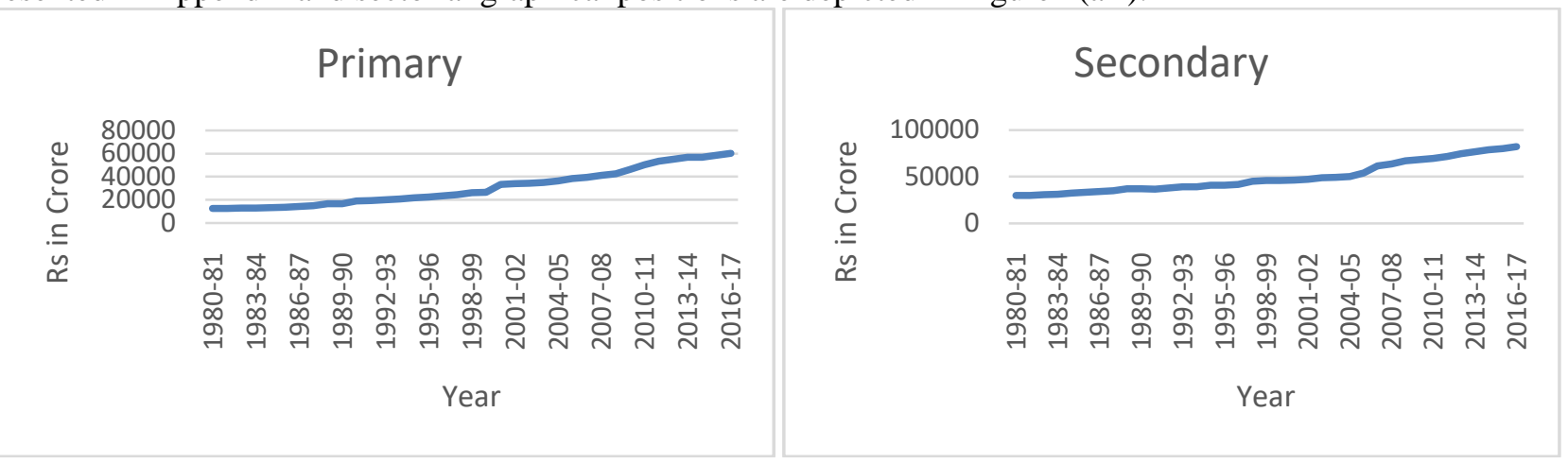

(a)(b)

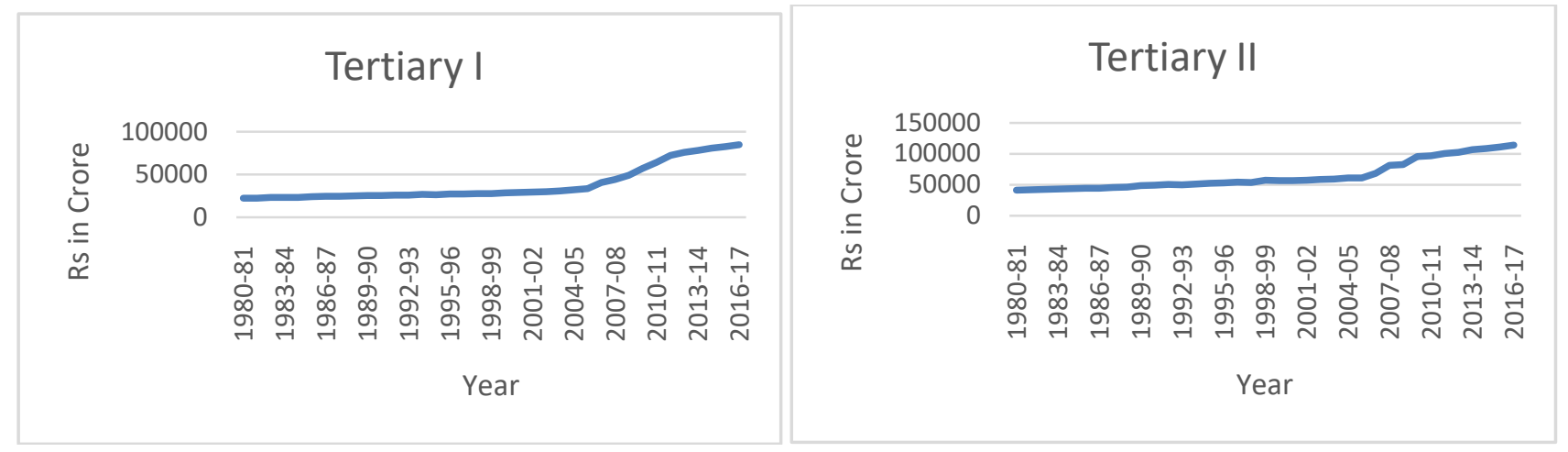

(c)(d)

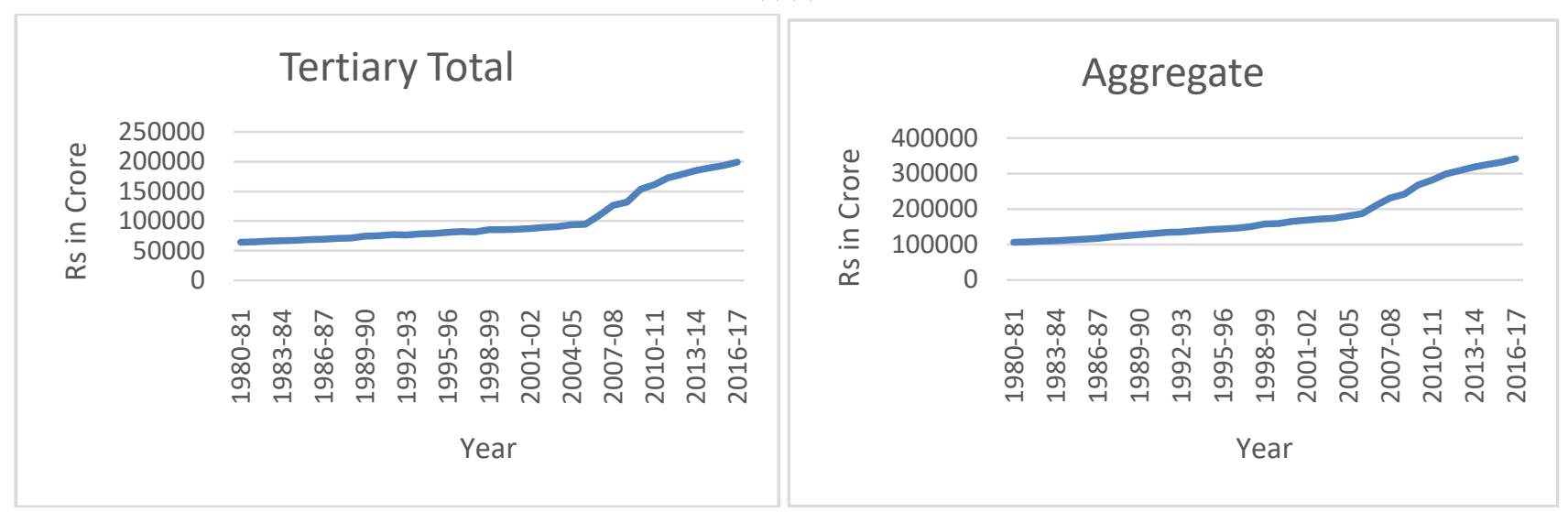

(e) (f)

Figure 1 
A broad look at these estimates indicates that the stock of capital in each of the activities, viz., primary; secondary; tertiary I; tertiary II; tertiary total; and aggregate has undergone growth-though at different pace and pattern. I. In primary sector, capital stock has grown from Rs 12624 crore in 1980-81 to Rs 60416 crore in 2016-17; yielding average annual growth rate of 4.72 percent. Capital stock in secondary sector and tertiary sector have shown average annual growth rate of 2.83 percent and 3.21 percent respectively-leading to average annual growth rate of overall average annual growth rate of overall capital stock in Bihar to 3.35 percent. Though a uniformly growing pattern was observed in each of the sectors, but the pace and pattern were studied in Table 1 and Table 2 for decadal and plan wise analysis.

Table 1. Decadal average annual growth rate in Bihar by main sectors

\begin{tabular}{ccccccc}
\hline Decades & Primary & Secondary & Tertiary-I & Tertiary-II & Tertiary-Total & Aggregate \\
\hline $1981-91$ & 4.26 & 2.44 & 1.37 & 1.47 & 1.44 & 2.09 \\
$1991-2001$ & 5.69 & 2.03 & 1.31 & 1.68 & 1.55 & 2.39 \\
$2001-11$ & 4.44 & 3.99 & 8.61 & 5.31 & 6.55 & 5.47 \\
$2011-17$ & 4.23 & 3.66 & 8.23 & 5.13 & 6.21 & 5.14 \\
\hline
\end{tabular}

Source: Authors' calculation

Table 2. Plan wise average annual growth rate in Bihar by main sectors

\begin{tabular}{|c|c|c|c|c|c|c|}
\hline Five-Year Plan & Primary & Secondary & Tertiary-I & Tertiary-II & Tertiary-Total & Aggregate \\
\hline Sixth & 1.35 & 2.13 & 1.01 & 1.45 & 1.30 & 1.59 \\
\hline Seventh & 5.73 & 3.42 & 1.73 & 1.27 & 1.40 & 2.48 \\
\hline Eighth & 4.02 & 1.36 & 1.11 & 2.15 & 1.80 & 2.01 \\
\hline Ninth & 8.98 & 2.87 & 1.78 & 1.08 & 1.31 & 3.10 \\
\hline Tenth & 3.67 & 6.09 & 7.91 & 3.88 & 5.30 & 5.20 \\
\hline Eleventh & 6.25 & 3.00 & 12.15 & 7.89 & 9.56 & 7.17 \\
\hline Twelfth & 6.21 & 2.89 & 10.24 & 7.53 & 9.42 & 7.03 \\
\hline
\end{tabular}

Source: Authors' calculation

Pace of growth during 1981-91 and 1991-2001 was slow but with relatively higher growth rate in primary sector. However, growth picked-up during 2001-11 with more focus on secondary sector and tertiary sector, while pace of growth reduced in primary sector. Slightly slower growth was noticed during truncated decade 2011-17 in all sectors. Plan wise analysis presented in Table 3 reveals that growth in capital stock was maximum during Tenth Plan in secondary sector and thereafter taken reverse turn while growth in capital stock in primary and tertiary sector were maximum during eleventh plan but growth trend slightly reduced during twelfth plan. Sector wise growth rates presented in Table 3 are graphically depicted below in Figure 1.

\section{Long-Term Trends in Components of NFCS:}

The long term trend analysis has revealed that the behavioral growth path followed by the net fixed capital stock is indicated in Table 3.

Table 3 indicates computation for the best-fit paths in respect of NFCS from various sectors in Bihar. Primary Sector was most appropriately represented by ordinary cubic function (CUB). This equation was associated with the maximum value of Index $(\mathrm{I}=1.078)$ with a very high value of co-efficient of Predictability $(\varnothing=0.917)$ out of seven equations tried. However, the accompanying value of D-W statistics (1.042), significantly less than 2 pointed towards the function to be infested with of auto correlated disturbance terms. The same (CUB) best fit path was identified to be prevalent in Aggregate Tertiary and Overall Economy. However, in respect of Secondary, Tertiary I and Tertiary II sectors cubic in logarithms (LCB) turned out to be the best fit function. Thus, the growth was either cubic or cubic on logarithms. Fit of long term trend path as indicated by maximum value of Index (I) and high value of co-efficient of predictability (Ø) was very satisfactory for all the sectors. Thus, the generated time series on all the components of net fixed capital stock have propagated in a closely predictable manner. 


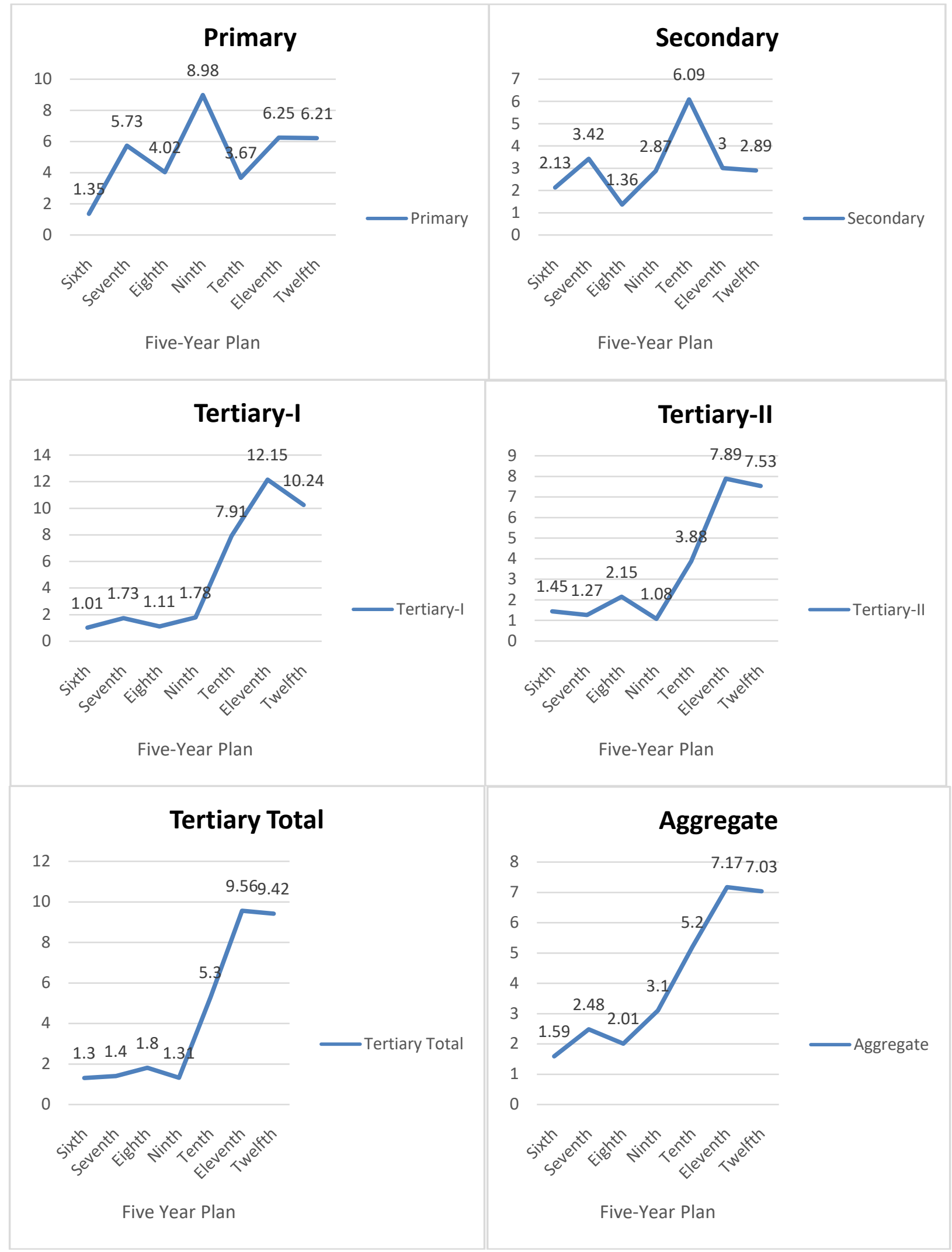

Figure 2 
Table 3. Best Fit Paths in respect of NFCS from various sectors-Bihar

\begin{tabular}{ccccccccc}
\hline \multirow{2}{*}{ Sector } & $\begin{array}{c}\text { Equation of the } \\
\text { Best-Fit. }\end{array}$ & \multicolumn{3}{c}{ Parameters of the Best-Fit Equation } & \multicolumn{2}{c}{$\begin{array}{c}\text { Co-efficie } \\
\text { nt }\end{array}$} & $\begin{array}{c}\text { D-W } \\
\text { Statistic }\end{array}$ & Index I \\
\hline 1 & 2 & 3 & 4 & b2 & 5 & 6 & 7 & 8 \\
Primary & CUB & 1.255 & $3.012 \times 10^{-2}$ & $6.901 \times 10^{-3}$ & $-1.209 \times 10^{-4}$ & 0.917 & 1.042 & 1.078 \\
Secondary & LCB & 0.964 & $-1.705 \times 10^{-2}$ & $6.062 \times 10^{-3}$ & $-1.709 \times 10^{-4}$ & 0.919 & 1.118 & 0.769 \\
Tertiary I & LCB & 1.016 & $1.962 \times 10^{-2}$ & $-8.556 \times 10^{-3}$ & $-6.923 \times 10^{-4}$ & 0.926 & 1.289 & 0.953 \\
Tertiary II & LCB & 0.980 & $3.972 \times 10^{-3}$ & $4.501 \times 10^{-4}$ & $-7.385 \times 10^{-4}$ & 0.903 & 1.563 & 1.139 \\
Tertiary-total & CUB & 0.996 & $4.798 \times 10^{-3}$ & $3.927 \times 10^{-3}$ & $-5.512 \times 10^{-5}$ & 0.909 & 1.073 & 1.409 \\
Aggregate & CUB & 0.988 & $1.498 \times 10^{-3}$ & $6.219 \times 10^{-3}$ & $-4.827 \times 10^{-5}$ & 0.901 & 1.636 & 1.191 \\
\hline
\end{tabular}

Source: Author's calculation

\section{Relative Growth Rates in NFCS}

Since the path of best-fit was either cubic or logarithm-cubic in various components of NFCS, either acceleration or deceleration hypothesis was prevalent in respect of growth in NFCS in Bihar at aggregated/disaggregated levels, Relative Growth Rates $\left(\mathrm{RGR}_{\mathrm{t}}\right)$ based on estimates of NFCS indicated in Appendix, versus time has been diagrammatically presented in Figure 3.

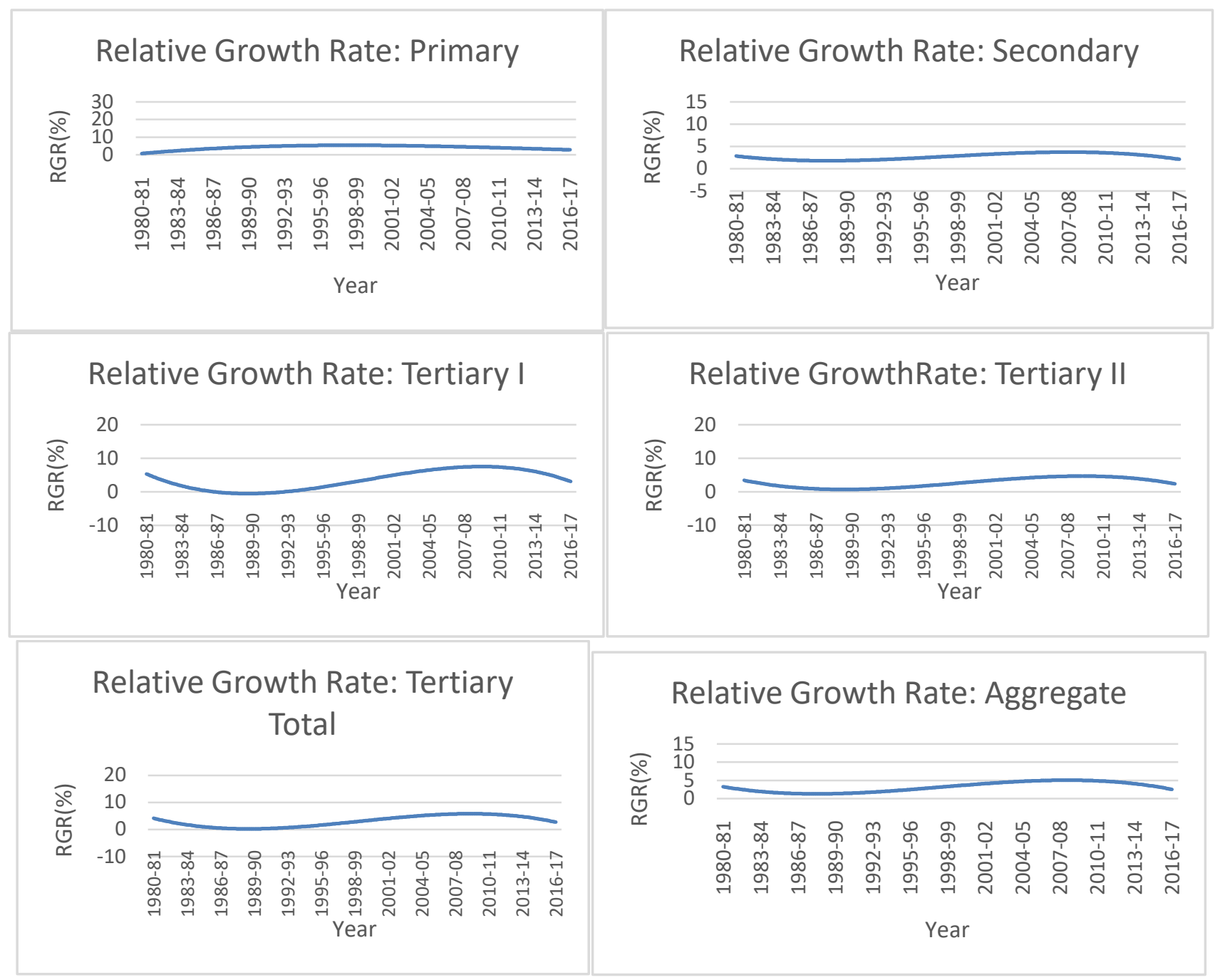

Figure 3 
These diagrammatical representations of relative growth rates "RGR," versus time "t" (Figure 3) indicate that the net fixed capital stock in Primary Sector of Bihar had no considerable acceleration but for the occasional bumps, while in Secondary Sector; Tertiary-1 Sector; \& Tertiary-2 Sector of Bihar acceleration in growth up to 2005-6 could not be visualized - though apparent rapid acceleration thereafter also declined. Aggregate Net Fixed Capital Stock of Bihar grew almost at constant growth rate up to 2005-6, then with a higher growth rate up to 2011-12 and thereafter had a declining growth.

\section{Turning Points}

Table 4 indicates number of turning points, kinked growth rates and pooled growth rates in various components of NFCS.

Table 4. Number of turning points, Kinked Growth Rates and Pooled Growth Rates in various components of NFCS

\begin{tabular}{|c|c|c|c|c|}
\hline Sector & $\begin{array}{l}\text { Number of } \\
\text { Turning Points }\end{array}$ & $\begin{array}{c}\text { Year of } \\
\text { Turning Points }\end{array}$ & Kinked Growth Rates in different segments & Pooled Growth Rates \\
\hline Primary & 2 & $\begin{array}{l}\text { 1989-90, } \\
2002-03\end{array}$ & $\begin{array}{c}1^{\text {st }} \text { Seg.: } 3.27^{* *} ; 2^{\text {nd }} \text { Seg.: } 5.31^{* *} \\
3^{\text {rd }} \text { Segment: } 4.33^{* *}\end{array}$ & $4.28^{* * *}$ \\
\hline Secondary & 2 & $\begin{array}{l}\text { 1988-89, } \\
2005-06\end{array}$ & $\begin{aligned} 1^{\text {st }} \text { Seg.: } & 2.06^{* *} ; \text { 2nd Seg.: } 2.29^{* *} \\
& 3^{\text {rd }} \text { Seg.: } 5.14^{* * *}\end{aligned}$ & $3.24^{* *}$ \\
\hline Tertiart-1 & 1 & 2005-06 & $1^{\text {st }}$ Seg.: $1.61^{*}$; 2nd Seg.: $13.79^{* * *}$ & $4.23^{* * *}$ \\
\hline Tertiary-2 & 1 & 2005-06 & $1^{\text {st }}$ Seg.: $1.55^{*} ; 2^{\text {nd }}$ Seg.: $8.63^{* * *}$ & $3.42^{* *}$ \\
\hline Tertiary-Total & 1 & 2005-06 & $1^{\text {st }}$ Seg.: $1.57^{*} ;$ 2nd Seg.: $10.54^{* * *}$ & $3.88^{* *}$ \\
\hline Aggregate & 1 & 2005-06 & $1^{\text {st }}$ Seg.: $2.28^{* *} ;$ 2nd Seg.: $8.08^{* * *}$ & $3.68^{* *}$ \\
\hline
\end{tabular}

Source: Author's calculation

*: Significant at $5 \%$ level; ${ }^{* *}$ : Significant at $1 \%$ level; ${ }^{* * *}$ : Significant at $0.1 \%$ level.

Table 4 reveals that excepting Primary Sector, all other sectors had a turning point in the year 2005-6 that reflected accelerated growth performance. The average annual growth rate of NFCS changed from $2.29 \%$ to $5.14 \%$ in Secondary sector; $1.61 \%$ to $13.79 \%$ in Tertiary-1 sector; $1.55 \%$ to $8.63 \%$ in Tertiary-2 sector; $1.57 \%$ to $10.54 \%$ in Tertiary-Total sector; and 2.28\% to $8.08 \%$ in Aggregate. The situation in Primary sector was just the opposite, as the second turning point that occurred in 2000-01 indicated decline in average annual growth rate of NFCS from $5.31 \%$ to $4.33 \%$ - which may be the result of recurrent wastage of capital stock in this sector due to frequent natural calamities affecting Bihar.

\section{Conclusion}

This paper fulfils the existing gap of non-availability of the estimates of Fixed Capital Stock for Bihar that could measure the extent to which production activity increases wealth and creates the conditions needed to continue the production of goods and services in future by following the standard approach in the literature for the period 1980-2017 and examine long term behavioral growth path therein. An important finding from this study is that Bihar underwent a massive accelerated growth performance in generation of capital stock in Aggregate (8.08\% per annum) since occurrence of turning point in 2005-06. Growth of capital stock in Secondary Sector (5.14\% per annum) was lower than the overall economy but that in Tertiary Sector (10.54\% per annum) specially Transport; Storage \& Communication; Trade, Hotel \& Restaurant witnessed higher growth pattern since occurrence of turning point in 2005-06. Primary Sector, which has about one-fifth share in capital stock, showed decelerated growth performance since occurrence of turning point in 2000-01. Since capital stock is known to be the engine of growth, decelerated growth performance of primary sector (mainly agriculture in Bihar) and lower growth performance in secondary sector (manufacturing, electricity \& construction) is a matter of concern for policy makers in the light of need of strong agriculture sector for Food Security and industrial \& infrastructure development. Decelerated trend in capital stock during Twelfth Plan is also a matter of concern for developing economy of Bihar. There is dire need to focus on reorientation of investment planning and strategy.

\section{References}

Bosworth, B., S. M. Collins, \& Yu-chin Chen. (1995). “Accounting for Differences in Economic Growth”. The Brooking Institution, 
working Paper No.115.

Boyce, J. K. (1986). “Kinked Exponential Models for Growth Rate Estimation”. Oxford Bulletin of Economics and Statistics, 48(4).

Central Statistical Office, Govt. of India. (2009). "National Accounts Statistics: Sources \& Methods”.

Cororation, C. B., \& Ma. T. D. Caparas. (1999). “Total Factor Productivity: Estimates for Philippine Economy”, PIDS discussion Paper Series No.99.

Das, D. K. (2004). “Manufacturing Productivity under Varying trade Regimes, 1980-2000”. Economic and Political weekly, 34(5).

Dhoakia, B. H. (1974). The Sources of Economic Growth in India, Good Companions, Baroda.

Dhoakia, B. H. (1977). “Growth of Factor Inputs and total Factor Productivity in Public Sector Enterprises”. Vikalpa, 2(2).

Directorate of Economics \& Statistics, Govt. of Bihar. (2016, 2017, 2018). "Bihar at A Glance”.

Directorate of Economics \& Statistics, Govt. of Bihar. (2016). "Bihar Statistical Handbook”.

Golder, B. (2004). “Indian Manufacturing: Productivity Trends in Pre- and Post- Reform Periods”. Economic and Political Weekly, 39(46/47).

Kruger, J. J. (2003). “The Global Trends of Total factor productivity: Evidence from the Nonparametric Malmquist Index Approach”. Oxford Economic Papers, 55.

Limam, Y. R., \& S. M. Miller. (2004). "Explaining Economic Growth: Factor Accumulation, Total Factor productivity Growth, and Production Efficiency Improvement”. University of Connecticut, Department of Economics, Working Paper.

Lutzel, H. (1977). “Estimates of Capital Stock by Industries in the Federal Republic of Germany”. Review of Income and Wealth, 23(1).

Musso, P. (2006). “Capital Obsolescence, Growth Accounting and Total Factor Productivity”. Revue de I’OFCE, 97(5).

Nehru, V., \& A. Dhareswar. (1993). “A New Database on Physical Capital Stock: Sources, Methodology and Results”. Revisita de Analisis Economico, 8(1).

Pradhan, G., \& K. Barik. (1999). “Total Factorproductivity Growth in Developing Economies-A Study of Selected Industries in India”. Economic and Political Weekly, 34(31).

Rajeswari, T. (2008). “Measurement of Capital Stock, Depreciation and Wealth”. The Journal of Income and Wealth, 30(2).

Sethi, A. S. (2008). "Some Methodological Aspects of Rates of Growth Computation: Limitations and Alternatives”. South Asia Economic Journal, 9(1).

Sethi, A. S., \& S. Kaur. (2012). “Estimation of Fixed Capital Stock: Comparative Analysis for Punjab and Haryana States”. The Journal of Income and Wealth, 34(2).

Sinha, J. K., \& A. Verma. (2015a). "Estimation of Capital Formation and Capital Output Ratio in Bihar (2004-05 to 2011-12)”. The Journal of Income and Wealth, 37(1).

Sinha, J. K., \& A. Verma. (2015b). “Trend \& Growth of Fixed Capital Stock in”. The Journal of Income and Wealth, 37(2).

Singh, T. (2001). “Total Factor Productivity in the Manufacturing Industries in India”. The Indian Economic Journal, 48(2).

Ware, G. O., K. Ohki, \& L. C. Moon. (1982). “The Mitscherlich Plant Growth Model for Determining Critical Nutrient Deficiency Levels". Agronomy, 74.

Wu, H. X., \& Xu, X. (2002). "Measuring the Capital Stock in Chinese Industry-Conceptual Issues and Preliminary Results”. 27th General Conference of international association for research in Income \& Wealth, Stockholm, Sweden. 
Appendix: Estimates of NFCS in Bihar by main sectors (at 2011-12 prices). (Rs. Crore)

\begin{tabular}{|c|c|c|c|c|c|c|}
\hline Year & Primary & Secondary & Tertiary-I & Tertiary-II & Tertiary Total & Aggregate \\
\hline 1980-81 & 12624.570 & 29924.446 & 22374.580 & 41676.974 & 64051.554 & 106600.570 \\
\hline 1981-82 & 12794.556 & 30047.444 & 22492.050 & 42286.436 & 64778.486 & 107620.486 \\
\hline 1982-83 & 12956.250 & 30919.486 & 23065.580 & 42970.526 & 66036.106 & 109911.842 \\
\hline $1983-84$ & 13131.764 & 31092.236 & 23335.070 & 43535.764 & 66870.834 & 111094.834 \\
\hline 1984-85 & 13319.716 & 32562.684 & 23290.846 & 44150.754 & 67441.600 & 113535.446 \\
\hline 1985-86 & 13499.376 & 33488.624 & 23937.622 & 44500.400 & 68438.022 & 115426.022 \\
\hline 1986-87 & 14417.024 & 34091.176 & 24396.446 & 44851.428 & 69247.874 & 117756.074 \\
\hline 1987-88 & 15091.440 & 34936.960 & 24603.746 & 45882.400 & 70486.146 & 121896.546 \\
\hline 1988-89 & 16643.426 & 37254.574 & 24934.044 & 46429.672 & 71308.436 & 125206.436 \\
\hline 1989-90 & 16870.074 & 37027.926 & 25504.810 & 49061.000 & 74565.810 & 128463.810 \\
\hline 1990-91 & 19153.138 & 36682.426 & 25647.156 & 49598.598 & 75245.754 & 131095.138 \\
\hline 1991-92 & 19317.596 & 38035.404 & 25822.670 & 50857.600 & 76680.270 & 134033.270 \\
\hline 1992-93 & 20091.516 & 39342.776 & 26057.610 & 50100.264 & 76157.874 & 135583.874 \\
\hline 1993-94 & 20902.750 & 39214.250 & 26949.000 & 51305.368 & 78254.368 & 138371.368 \\
\hline 1994-95 & 21882.588 & 40702.664 & 26538.546 & 52464.866 & 79003.412 & 141588.664 \\
\hline $1995-96$ & 22616.430 & 40955.570 & 27287.590 & 53207.000 & 80494.590 & 144066.590 \\
\hline 1996-97 & 23525.786 & 41533.246 & 27228.164 & 54554.450 & 81782.614 & 146841.646 \\
\hline 1997-98 & 24471.074 & 45122.300 & 27630.326 & 53907.674 & 81538.000 & 151131.374 \\
\hline 1998-99 & 26450.098 & 46092.464 & 27926.074 & 57565.828 & 85491.902 & 158034.464 \\
\hline $1999-2000$ & 26479.120 & 46075.880 & 28766.330 & 56827.840 & 85594.170 & 159531.170 \\
\hline 2000-01 & 33315.874 & 46513.974 & 29216.862 & 56941.164 & 86158.026 & 165987.874 \\
\hline 2001-02 & 34178.242 & 47359.758 & 29598.294 & 57477.380 & 87075.674 & 168613.674 \\
\hline 2002-03 & 34346.846 & 48711.354 & 30115.162 & 59097.084 & 89184.606 & 172270.446 \\
\hline 2003-04 & 35044.756 & 49257.244 & 30869.734 & 59449.494 & 90319.228 & 174621.228 \\
\hline 2004-05 & 36678.28 & 50375.282 & 32113.534 & 61239.184 & 93352.718 & 180406.280 \\
\hline 2005-06 & 38430.656 & 54163.344 & 33375.300 & 61222.600 & 94597.900 & 187191.900 \\
\hline 2006-07 & 39674.456 & 61706.300 & 40838.100 & 68823.600 & 109661.700 & 211042.456 \\
\hline 2007-08 & 41193.274 & 63838.726 & 44374.638 & 81883.500 & 126258.138 & 231290.138 \\
\hline 2008-09 & 42777.046 & 67234.300 & 49130.100 & 82643.600 & 131773.700 & 241785.046 \\
\hline 2009-10 & 46290.090 & 68415.910 & 57353.000 & 95975.754 & 153328.754 & 268034.754 \\
\hline 2010-11 & 50517.628 & 69716.372 & 64489.648 & 96878.200 & 161367.848 & 281601.848 \\
\hline 2011-12 & 53730.778 & 71546.140 & 72458.260 & 100609.600 & 173067.860 & 298344.778 \\
\hline 2012-13 & 55330.887 & 74516.410 & 75852.620 & 102906.732 & 178759.352 & 308606.649 \\
\hline 2013-14 & 56841.142 & 76615.887 & 78258.262 & 106609.237 & 184867.499 & 318324.528 \\
\hline 2014-15 & 57148.241 & 78715.615 & 80884.457 & 108975.726 & 189810.183 & 325674.039 \\
\hline 2015-16 & 58641.826 & 80122.516 & 82488.754 & 111103.124 & 193591.878 & 332356.220 \\
\hline 2016-17 & 60416.682 & 82221.321 & 84844.457 & 114301.433 & 199145.890 & 341783.893 \\
\hline
\end{tabular}

Source: Authors’ calculation. 